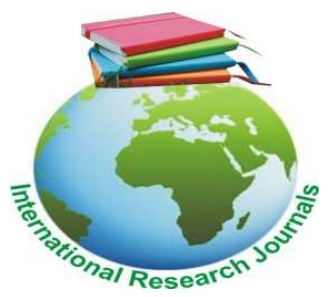

Educational Research (ISSN: 2141-5161) Vol. 8(3) pp. 034-038, June, 2017

Available online@ http://www.interesjournals.org/ER

DOI: http:/dx.doi.org/10.14303/er.2017.025

Copyright (@ 2017 International Research Journals

\title{
Review
}

\section{Childhood immunization in Nigeria: factors influencing noncompliance}

\author{
*Adebiyi Joseph A. and Ajani Taiwo A. \\ Nurse, Babcock University Teaching Hospital, llishan-Remo. Ogun State \\ ${ }^{*}$ Corresponding Author's Email: Josephadebiyi31@gmail.com
}

\begin{abstract}
The challenges facing childhood immunization coverage, coupled with the dramatic resurgence of preventable diseases suggest that current strategies to ensure positive result in national immunization programmes in Nigeria needs to be examined. Immunization is one of the most cost-effective public health interventions to date, saving millions of lives and protecting countless children from illness and disability. Despite the availability of vaccines to tackle preventable childhood diseases, they remain endemic in the sub-Saharan region including Nigeria. This paper seeks to investigate the factor influencing childhood immunization noncompliance among the nursing mothers in Nigeria and Suggest possible way out. Numerous studies have shown that some of these factors responsible for immunization noncompliance are parent socio-demographic characteristics such as level of education on the issues of vaccination/immunization, occupation, cultural beliefs, traditions among others age of parents, parental economic status, and health related factors. Immunization remains a major way to reduce child mortality and morbidity in Nigeria, although availability and high immunization coverage may not be enough to ensure effective childhood immunization exercise. Based on the findings of these studies. It is recommended that the Nigerian government should intensify efforts in ensuring the effectiveness of childhood immunization. The following approach are suggested towards solving childhood immunization problem, Legislative approach, Economic approach, Religious approach, Basic education for the nursing mothers.
\end{abstract}

Keywords: Childhood immunization, Nursing mothers, Immunization coverage.

\section{INTRODUCTION}

Immunization is one of the most cost-effective public health interventions to date, saving millions of lives and protecting countless children from illness and disability. Consequently, polio is on the verge of eradication globally. Deaths from measles, is a major child killer, which declined by 79 per cent worldwide and by 86 per cent in sub-Saharan Africa between 2000 and 2014. As of August 2015, 38 of 59 priority countries (UNICEF, 2016). The aim of giving immunization to children is to provide primary prevention against communicable diseases or killer diseases during infancy or childhood. These include polio vaccine, diphtheria, pertusis, and tetanus vaccine, measles vaccine (Federal Ministry of Health, 2005), hepatitis B and yellow fever vaccine (World Health Organization, 2005), among others.

Vaccines preventable diseases include diphtheria, pertussis, measles, poliomyelitis, tuberculosis, cerebrospinal meningitis, hepatitis and yellow fever (Antai, 2012). These diseases accounted for approximately 872,000 deaths in 2012 which represented $22 \%$ of under-five mortality. According to Folliden (2015) it is estimated that over 200,000 children die yearly from vaccine preventable diseases.

According to Birhanu et al. (2016), the objectives of Program on Immunization in many part of Sub Sahara Africa such as Nigeria has not been met because of low level of knowledge among parents regarding infant immunization regardless of socioeconomic categories and poor nursing mother's immunization noncompliance (Selvaraj, Sarkar and Daya, 2014).

According to NDHS (2013) Nigeria currently practice National Expanded Programme on Immunization, this mirrors the international recommendation by WHO. A child is considered fully immunized if he or she had 
received one BCG vaccine against Tuberculosis at birth; three doses of vaccine to prevent diphtheria, pertussis, and tetanus; at least three doses of polio vaccine; and one dose of measles vaccine. According to WHO all this vaccine should be received within the first birthday. According to NHDS (2013) only 21 percent of children age 12-23 months had received all of the recommended vaccinations before their first birthday in Nigeria, while overall 25 percent of children age 12-23 months were fully vaccinated at the time of the survey by NHDS.

This is far below world health organization (WHO) target of $80 \%$. The situation is worst in the rural area as children in this area are twice less likely to receive full basic immunization (Adedire et al 2016).To this end, this study investigates the factors influencing childhood immunization noncompliance among nursing mothers in Nigeria and suggests way out.

Significantly, the findings of this study fills the gap of paucity of data on factors influencing childhood immunization noncompliance among nursing mothers. It also shows the factors that contribute to Childhood immunization compliance. Consequently, it will serve as an eye opener and a guide for government at all levels the best approach to reduce dropout rate and improve on immunization compliance in Nigeria. This will go a long way in increasing childhood immunization compliance and reducing maternal and child mortality rate.

\section{Routine immunization of infants in Nigeria}

According to WHO (2010), schedules are provided for immunization of children. These calls for all children to receive one dose of BCG vaccine, 3 doses of Pentavalent vaccine, 4 doses of OPV, and one dose of measles vaccine before the first birthday. Nigeria is part of the countries with $\mathrm{HBsAg}$ carriage rates of $2 \%$ or more, universal infant immunization with $H B$ vaccine is recommended. Countries with a lower HBV prevalence may consider immunization of all adolescents as an addition or alternative to infant immunization.

According to Mojoyinola and Olaleye (2013), Nigeria currently operates the immunization schedule of the expanded programme on immunization which prescribe five visit such as follows; at birth the child receives one dose of Bacilli Calmate Guarine (BCG), first dose of oral polio vaccine (OPV1) and first dose of hepatitis $B$ vaccine (HBV0). At second Visit which is six weeks the child receives OPV1, Pentavalent 1 (this contains Diptheria, Pertussis, Tetanus vaccine - DPT + Hepatitis B Vaccine $\mathrm{HBV}+$ Hemophilus influenza type b vaccine - Hib.) and first dose of pneumococcal conjugate vaccine (PCV1). At $10+$ weeks which is the third visit, the child receives OPV2, pentavalent 2, and PCV2. At 14 weeks the child receives OPV3, Pentavalent $3, \mathrm{PCV} 3$ and the last visit at 9 months the child receives one dose of measles, one dose of yellow fever and first dose of vitamin A. At 15 months the child gets the second dose of vitamin A (The Health Team, 2012).

The following are the specific immunization according to when it is given:

- BCG - At birth or as soon as possible after birth

- OPV - At birth and at 6, 10, and 14 weeks of age

- Pentavalent Vaccine - At 6, 10 and 14 weeks of age

- PCV - At 6, 10 and 14 weeks of age

- Yellow fever vaccine Vitamin A1 and Measles - At 9 months of age.

- Vitamin A2 - At 15 months of age.

\section{National immunization coverage survey}

Immunization is coordinated by the National Programme on Immunization (NPI), a parastatal of the Federal Ministry of Health in collaboration with the State Ministries of Health and local government health centres, UNICEF and WHO. It was established by the Federal Government of Nigeria in 1997 (Folliden, 2005).

Nigeria has 774 local government areas subdivided into 5,450 districts, within which there are villages and 9,555 wards. These vast areas are expected to be covered for immunization programmes. Previously, the programme was co-ordinated by Expanded Programme on Immunization with multinational donor agencies. According to Folliden (2005), immunization coverage in Nigeria has become a major challenge in the context of child survival strategy, and the Nigerian immunization coverage is far below some countries in conflict. The DPT3 immunization coverage varied from $5 \%$ in 1984 to $29 \%$ in 2000 with peak coverage of $57 \%$ attained in 1990 . A dramatic decline to $28 \%$ was observed in 2001 . A target of $95 \%$ immunization coverage against vaccine preventable diseases is necessary for sustained control of vaccine preventable diseases.

The national average for children who received all the basic immunization was 25 percent which was very low given that A World Fit for Children goal is to ensure full Immunization of children less than one year of age at 90 percent nationally, with at least 80 percent coverage in each state. Even among states that had coverage above the national average, none was able to reach this target of 80 percent coverage in all basic immunization (NDHS, 2013).

World Health Organization argues that drop-out rate of more than $10 \%$ is not acceptable and is dangerous for any country. The national immunization coverage reported in 2003 was $12.7 \%$ indicating further decline from $28 \%$ reported in 2001 .Sources of immunization in 2003 were as follows: government $75.6 \%$, private $8.4 \%$, non-governmental agencies $1.7 \%$. Reasons for non immunization were non availability of vaccines, distant and unknown immunization sites, fear of adverse reactions from vaccines, rumours, lack of trust in immunization and mother not having time for 
immunization. Folliden (2005) has it that about $23 \%$ of children was fully immunized in 2008, while those without any immunization was $29 \%$. The Fully immunized children were highest in south-eastern zone (43\%) and least in north-western zone (6\%).

Significant variations were noted between urban and rural areas, with more coverage observed among urban population (38\% versus $16 \%$ respectively). UNICEF reported coverage of $69 \%$ for DPT3 in 2010 but insisted Nigeria must intensify her campaign, as some states had poor coverage (World Health Organization 2011). NPI has been faced with the challenge of storage, distribution of vaccines, monitoring and evaluation of immunization activities, along with the submission of its annual report on immunization coverage to $\mathrm{WHO}$. It was reported that cold chain facilities at the state levels were poorly equipped and managed, with over half of the refrigerators being worn-out in 2005. Collaboration of staff at different levels has also been a major challenge. Migration was implicated as a risk factor for non-immunized affected children. Outbreaks of poliomyelitis were reported in Europe and were linked to importation from endemic countries (Antai, 2010).

From 2006 to 2010, Nigeria nearly tripled the proportion of children covered by routine immunization, according to the National Immunization Coverage Survey (NICS), conducted in October 2010. The increase took place against the backdrop of aggressive Supplementary immunization campaigns to eradicate polio. The results of the 2010 NICS indicate that $52 \%$ of Nigerian children aged 12-23 months are reported to be fully immu0nized, compared with just $18 \%$ in 2006 . In 2003 , when the first baseline study was undertaken, the corresponding figure stood at just $13 \%$.

The NICS aims to estimate the levels of immunization coverage at national, regional and state levels. The survey is regarded by the Nigerian Government and international partners as the most accurate measure of routine immunization services, providing important insights into community and individual attitudes towards immunization. More than 19,000 households in selected settlements of every state were visited in October 2010 by trained representatives of an independent research company. Coverage was determined by vaccination card and the child's history as recounted by the family at 52 weeks of age. Coverage of DPT3 - a measurement of the number of children who are fully protected against three killer diseases Diphtheria, Pertussis and Tetanus and the most common measurement of basic routine services - increased nationally from $25 \%$ in 2006 to $68 \%$ in the 2010 study. Advances were recorded in all regions of the country.

The national average distribution of children between 12 - 23 months who received all basic immunization and those who did not receive as at 2013 was 25 percent. This is very low given that A World Fit for Children goal is to ensure full Immunization of children less than one year of age at 90 percent nationally, with at least 80 percent coverage in each state. No state was able to reach this target of 80 percent coverage in all basic immunization (State of Nigerian children report 2015).

According to NDHS (2013) between year 2008 and 2013, almost one in four children does not receive any routine immunization. Overall, 25 percent of children age 12-23 months were fully vaccinated at the time of the survey. This represents a 9 percent increase from the figure reported in the 2008 NDHS and is nearly double the figure reported in 2003. Twenty-one percent of eligible children received no vaccination at all. While this figure represents a 28 percent improvement over that recorded in the 2008 NDHS. As for coverage of specific vaccines among children age 12-23 months, 51 percent had received the BCG vaccine, and 42 percent had received the measles vaccine. While 51 percent received the first dose of the DPT vaccine, only 38 percent went on to receive the third dose, reflecting a dropout rate of 25 percent. Although only 47 percent of children received there commended polio 0 dose at birth, 77 percent received the first dose, 70 percent received the second dose, and 54 percent received the third dose. The wide difference in DPT and OPV coverage is accounted for by the national and subnational immunization day campaigns during which the polio vaccine is administered. Overall, only 21 percent of children age 1223 months had received all of the recommended vaccinations before their first birthday, this is by far very low compare with WHO target of at least $80 \% \mathrm{NDHS}$ (2013).

\section{Factors influencing childhood immunization compliance/noncompliance in Nigeria}

Supply of vaccine has been the main reason attributed to be the problem of low vaccination in Nigeria (Jegede and Owumi, 2013). Also, problems of finance, procurement, cold chain maintenance and weak or collapsed primary health care system were indicated in the reports (FBA, 2005). Demand for vaccination was considered to be mere knowledge and education issues (Omar, 2009; Ogilvie, Anderson, Marra, McNeil, and Pielak, 2010). Furthermore, Jegede and Owumi (2013) stated that culture of the people could also have effect on childhood immunization uptake. Tarrant and Gregory (2003) also stated that, childhood immunization uptake is adversely influenced by factors that include parental misperceptions, vaccine side-effects, negative outcomes from vaccination, and health-care system barriers.

Also, barriers to immunization could be grouped into systems barriers (e.g., those involving the organization of the health care system and economics), health care provider barriers (e.g., inadequate clinician knowledge about vaccines and contraindications to their use), and parent or patient barriers (e.g., fear of immunization 
related adverse events) (Kimmel, Burns, Wolfe and Zimmerman, 2007).

Kimmel, Burns, Wolfe and Zimmerman (2007) also stated that logistical barriers are another challenge that militates against immunization uptake. Logistic barriers faced by health care providers include the cost of immunizations, vaccine storage or capacity, and lack of access to patients' prior immunization records. Vaccines with stringent storage requirements, such as varicella vaccine or live attenuated influenza vaccine, may present a challenge and fragmentation of patient care makes it more likely that providers will not have complete immunization records for patients currently in their care (Kimmel et al., 2007).

Studies such as those of Luman, et al. (2003) and Kim, Frimpong et al. (2006) have shown that some of the factors influencing immunization compliance are young age of parents, low level of parental education, birth order of the child (which are socio-demographic characteristics of parents), financial barriers such as low family income. Also, Swennen et al., (2001); Zucs et al. (2004) and O'Connor and Bramlett (2008) have also revealed that, the lack of health insurance and gaps in the relevant infrastructures such as lack of periodic primary health care access, or decreased availability of health care facilities are major factors militating against immunization compliance.

WHO (2010) drew attention to the behavioural factors of parents especially nursing mothers as major factors influencing immunization compliance. Furthermore, parent socio-demographic characteristics such as education on the issues of vaccination/immunization, occupation, among others were also important (Babatsikou et al., 2010). Also, Mojoyinola and Olaleye (2012) stated that the psychological factor of mothers such as their attitudes to immunization, knowledge about immunization are major factors to be considered influencing immunization compliance. Furthermore, physical factors such as location of immunization services/access to immunization centres/distance to immunization services are major factors that may affect the success of immunization processes (Mojoyinola andOlaleye, 2012). In addition, health care provider barriers such as inadequate clinician knowledge about vaccines and contraindications to their use, lack of care or negligence, insulting individuals who come for one hospital services or the other, among health providers also constitute major issues to be considered in the study of immunization compliance.

\section{CONCLUSION}

Based on the findings of this study, it is now glaring that among diseases preventive measures known to man, immunization stands out as important and effective way of protecting people from disease especially among children, (Babatsikou et al., 2010). It is interesting to note that we now have immunization against some disease that was causing major public health challenges in the past, an example is polio. However, despite the availability of vaccines to tackle preventable childhood diseases, they remain endemic in the sub-Saharan region (Antai 2010).

So many factors have been associated with low immunization up take thereby contributing to high childhood mortality and high childhood morbidity. Factors such as physical factors, psychological factors, health related factors, level of education of the mother etc. it is worthy of note that mothers play a key role in ensuring their children gets immunized.

Numerous studies have shown that childhood immunization is a major tool in reducing the skyrocketing childhood mortality and morbidity rate in Nigeria. It is only expedient for the governments and decision makers to intensify effort on effectiveness of the programme.

\section{RECOMMENDATIONS}

Based on the findings of this studies in order to improve childhood immunization compliance among nursing mothers the following are recommended

1) Basic education for the nursing mothers: Studies have shown that childhood immunization noncompliance is high among illiterate mothers, while children of mothers with basic education showed the highest coverage. This calls for urgent need for the government to set goals and implement policies which will aim at reducing the number of illiterate persons and ensure education for all in Nigeria.

2) Religious approach: There is no official religion in Nigeria. Therefore, Citizen are at liberty to worship at will. To increase the immunization rate of Nigerian children the religious leaders need to be carried along. Nonimmunization status of children was associated with Muslim religion which limit access to immunization centers. Health education of religious leaders at worship centers will go a long way influencing a positive change regarding immunization

3) Economic approach: research has shown that income of parents is a major factor influencing immunization compliance as they miss immunization schedule due to lack of finance. Despite the effort by the government to subsidized childhood immunization, it is no news that majority of health workers at various primary health centres and places where immunizations are given still demand money from mothers all over the nation before immunizing their children. Health care personnel caught demanding money or any illegal pay before immunization is given should be seen as a saboteur of a good will from by the government and should be severely sanctioned. A tax force could be set up by Government at local level to monitor immunization exercise. 
038 Educ. Res.

4) Legislative approach: There is an urgent need for the legislative arms of the government to enact laws which will criminalize immunization noncompliance. This will protect the children and ensure more children are immunized thereby decreasing immunization noncompliance and decreasing the high child mortality and morbidity ravaging our society.

\section{REFERENCES}

Abbas UB, Chowdhary AM (2005). Knowledge and attitude of women towards Immunization. Online J. Health and Allied Sciences, 25(8), 25-32.

Adedire EB, Ajayil Fawole O, Ajumobi O, Kasasa S, Wasama P, Nguku $P$ (2016). Immunization coverage and its determinants among children aged 12-23months in Atakumosa- west districts, Osun State Nigeria: a cross sectional study. BMC Public Health; 10.1186/s 12889-0616-3531-x

Antai D (2010). Migration and Child immunization in Nigeria: individual and community Level Contexts. BMC Public health. 2010; 9(10): 116.

Babatsikou F, Vorou R, Vardaki Z, Galani S, Ktenas E, Koutis C (2010). Childhood vaccination uptake and factors affecting this in Athens, Greece, Health Science Journal, 4 (4). www.hsi.gr

Birhanu S, Anteneh A, Kibie Y, Jejaw A (2016). Knowledge, Attitude and Practice of Mothers Towards Immunization of Infants in Health Centres at Addis Ababa, Ethiopia, American J. Health Res. 4(1),617. science publishing group, http://www.sciencepublishinggroup.com///ajhr

FBA (2005). the state of routine immunization services in Nigeria and reasons for current Problems. FBA Health Systems Analysts, Report for DFID

Folliden B (2005) Health System Analysts; the State of Routine Immunization Services in Nigeria and Reasons for Current Problems. June 2005; 3-42. Retrieved from: www.phfn.org.

Mojoyinola JK, Olaleye BA (2012). Physical and Psychological Factors Influencing Maternal Non-Compliance with Immunization Schedule. Continental J. Nursing Science 4 (2): 37 - 51, ISSN: 2141 - 4173 , Wilolud Journals, http://www.wiloludjournal.com

Jegede AS, Owumi BE (2013). Factors Influencing Infant Immunization Uptake in the Yoruba Community of South Western Nigeria, $J$ Community Med Health Educ, 3:4, Community Medicine and Health Education
USAID (2007). Strengthening routine immunization services and sustainable financing for

Immunization. USAID from the American people. Retrieved from web http://www.immunizationbasics.jsi.com/About.htm

Ogilvie G, Anderson M, Marra F, McNeil S, Pielak K (2010). A Population Based Evaluation of a Publicly Funded, School-Based HPV Vaccine Program in British Columbia, Canada: Parental Factors Associated with HPV Vaccine, Receipt, PLOS Med 7:e1000270

Kimmel S, Madlon-Kay D, Burns I, Admire J (1996). Breaking the barriers to childhood Immunization. American Family Physician. 53 (5): 1648-1656.

Kim SS, Frimpong JA, Rivers PA, Kronenfeld JJ (2006), Effects of maternal and provider Characteristics on up-to-date immunization status of children age 19 to 35 months. Am J Public Health 2007, Feb; 97(2):259-66. Epub 2006 Dec 28.

Luman ET, McCauley MM, Shefer A, Chu SY (2003). Maternal characteristics associated With vaccination of young children. Paediatrics111(5):1215-8.

O'Connor KS, Bramlett MD (2008). Vaccination coverage by special health care needs Status in young children. PaediatricsApr; 121(4):e768-74.

Selvaraj K, Sarkar S, Daya PA (2014). Knowledge on routine pentavalent vaccines and Socioeconomic correlates among mothers of children aged younger than 5 years in Urban Puducherry, International J. Med. Sci. and Public Health, 4(2), http://www.ijmsph.com

Swennen B, Van Damme P, Vellinga A, Coppieters Y, Depoorter AM (2001). Analysis of factors influencing vaccine uptake: perspectives from Belgium. Vaccine; 20:S5-7.

Zucs AP, Crispin A, Eckl E, Weitkunat R, Schlipkoter U (2004).Risk factors for Under vaccination against measles in a large sample of preschool children from rural Bavaria. Infection; 32(3):127-33.

World Health Organization (WHO) (2005). expanded programme on immunization. WHO African Region: Nigeria. Retrieved from http://www.who.int/countries/nga7abouten

World Health Organization (2009). Epidemiology of the Unimmunized Child. Findings from the Peer Reviewed Published Literature, 1999 - 2009. Prepared for the World Health Organization, December 2009.

World Health Organization (WHO). (2010), Department of Vaccines and Biological. WHO.

Vaccines for Preventable Diseases: Monitoring System. Geneva: WHO; 2010. 